\section{Magnetna rezonanca}

Rade R. Babić1,2, Strahinja Babić ${ }^{6}$, Aleksandra Marjanović ${ }^{6}$, Dimitrije M. Pavlović ${ }^{6}$, Milorad Pavlović ${ }^{3}$, Gordana

Stanković-Babić4,5

${ }^{1}$ Centar za radiologiju KC Niš

${ }^{2}$ Visoka zdravstvena škola strukovnih studija »Hipokrat« u Bujanovcu

${ }^{3}$ Služba za patologiju, Opšta bolnica Leskovac

${ }^{4}$ Klinika za očne bolesti KC Niš

${ }^{5}$ Medicinski fakultet Univerziteta u Nišu

${ }^{6}$ Studenti Medicinskog fakulteta Univerziteta u Nišu

\section{Apstrakt}

Magnetna rezonanca (MR, Magnetna rezonantna tomografija - MRT, Nuklearna magnetna rezonanca - NMR, engleski: Magnetic Resonance Imaging - MRI) je savremena nejonizujuća, neinvazivna radiološka metoda pregleda kojom se vizualizuju i dijagnostikuju anatomska, morfološka i funkcionalna stanja organa ljudskog tela. MRI predstavlja samo jednu od karika radiološkog informacionog sistema. Rad MR se zasniva na primeni jakog homogenog magnetnog polja i savremene računarske tehnike. $\mathrm{U}$ radu su prikazani osnovni magnetne rezonance, istorija magnetne rezonance, jačina magnetnog polja kod MR, fizički principi MR, principi rada MR i sekvence MR.

Zaključak: Magnetna rezonanca je suverena, dominantna i nejonizujuća radiološka metoda pregleda, čije su tehnike snimanja obogatile radiološku sliku patoloških stanja organa, a za čiji je rad potrebno adekvatno znanje iz fizike, medicine, informatike i dr.

Keywords: Radiologija, magnetna rezonanca, tesla

\section{Uvod}

Magnetna rezonanca (MR, Magnetna rezonantna tomografija - MRT, Nuklearna magnetna rezonanca - NMR, engleski: Magnetic Resonance Imaging - MRI) predstavlja jedan od revolucionarnih pronalazaka u medicini koja je radiologiju učinila modernom, savremenom i kompleksnom dijagnostičkom granom medicine ${ }^{1-27}$. MR je nejonizujuća i neinvazivna radiološka metoda pregleda kojom se vizualizuju i dijagnostikuju anatomska, morfološka i funkcionalna stanja organa ljudskog tela. Rad MR se zasniva na primeni jakog homogenog magnetnog polja i savremene računarske tehnike za obradu virtualne MR slike u digitalnu. MR je samo jedna od karika radiološkog informacionog sistema (RIS) ${ }^{8-13}$. Jačina magnetnog polja MR aparata izražava se jedinicom tesla $(\mathrm{T})^{22-27}$.

MATERIA MEDICA • Vol. $30 \bullet$ No. $2 \bullet$ april 2014.
Rade R. Babic ${ }^{1,2}$, Strahinja Babic ${ }^{6}$, Aleksandra Marjanovic ${ }^{6}$, Dimitrije M. Pavlovic ${ }^{6}$, Milorad Pavlovic ${ }^{3}$, Gordana Stanković-Babic ${ }^{4,5}$

${ }^{1}$ Centar of Radiology, Clinical Center Nis

${ }^{2}$ High Medical School of Professional Studies ,Hippocrates“ in Bujanovac ${ }^{3}$ Department of Pathology, General Hospital Leskovac

${ }^{4}$ Department of Ophthalmology, Clinical Centre Nis

${ }^{5}$ Faculty of Medicine, University of Nis

${ }^{6}$ Students of the Faculty of Medicine, University of Nis

\section{Abstract}

Magnetic resonance imaging (MRI, magnetic resonance tomography - MRT, nuclear magnetic resonance - NMR, English: Magnetic Resonance Imaging - MRI) is a modern non-ionizing, noninvasive radiological methods of examination which visualize and diagnose anatomical, morphological and functional state of the organs of the human body. MRI is the only one of the important radiological information system. The work of MR is based on the application of a strong homogeneous magnetic field and modern computer technology. This paper presents the basic MRI, history of MRI, magnetic field strength in MR, MR physical principles, principles of MR and MR sequences.

Conclusion: MRI is a sovereign, dominant and non-ionizing radiological examination method, which are enriched radiological imaging techniques of pathological states authority, and whose work requires appropriate knowledge of physics, medicine and computer science.

Ključne reči: radiology, magnetic resonance imaging, tesla 


\section{Istorija magnetne rezonance}

Edvard Parcel (engleski: Edward Mills Purcell; 1912 - 1997) i Feliks Bloh (nemački: Felix Bloch; 1905 1983) su 1946. g. prvi, nezavisno jedan od drugog, otkrili NMR (slika 1). Edvard Parcel demonstrirao je rad NMR u jednom litru parafina u čvrstom stanju, dok je Feliks Bloh prikazao rad NMR u vodonikovim jezgrima $2 \mathrm{~cm}^{3}$ vode. Za ovo otkriće Edvard Parcel i Feliks Bloh su 1952 g. podelili Nobelovu nagradu za fiziku ${ }^{14,15}$.

Pol Kristian Loterbur (engleski: Paul Christian Lauterbur) i ser Piter Mensfild (engleski: Sir Peter Mansfield) su prvi, nezavisno jedan od drugog, MR primenili u dijagnostičke svrhe kod ljudi i za to otkriće su 2003.g. podelili Nobelovu nagradu za filiologiju i medicinu (slika 1) ${ }^{16,17}$.

Od 1950.g. do 1970.g. NMR se neprekidno razvijala i korišćena je samo za hemijske i fizičke analize.

Prva studija MR na čoveku objavljena je 1977.g.

Američko udruženje radiologa je 1983. g. predložilo da se iz naziva nuklearna magnetna rezonanca, izostavi naziv nuklearna kako bi se otklonile negativne predrasude prema jozujućem zračenju. Od tada je NMR dobila novi naziv - Magnetic Resonance Imaging (MRI) ili samo magnetna rezonanca (MR) ${ }^{9}$.

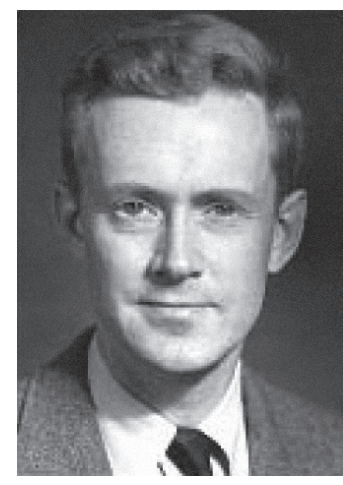

Edward Mills

Purcell

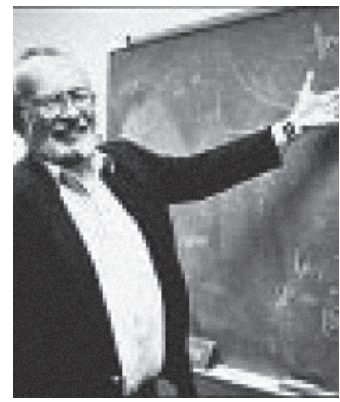

Paul Christian

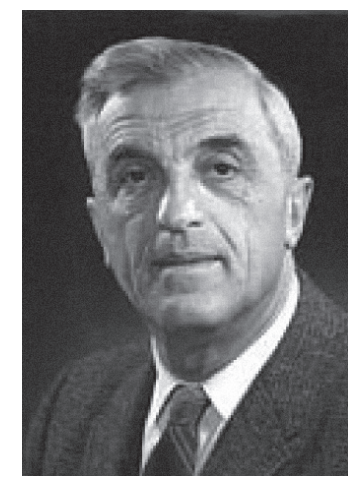

Felix Bloch

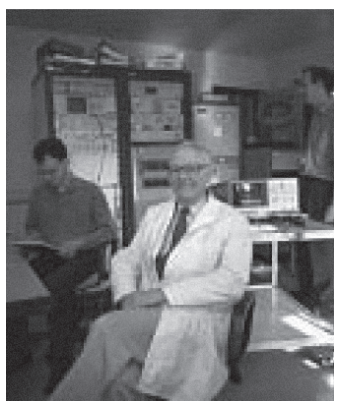

Sir Peter Mansfield Lauterbur

Slika 1. Edvard Parcel i Feliks Bloh su 1952 g. podelili Nobelovu nagradu za fiziku, dok su Pol Kristian Loterbur i ser Piter Mensfild 2003.ggodine podelili Nobelovu nagradu za filiologiju i medicinu ${ }^{14-17}$.

Kod nas, u našoj sredini, prvi opis rada i primene MR u dijagnostičke svrhe dao je profesor radiologije Medicinskog fakulteta Univeziteta u Nišu dr Radomir Babić sa radovima "Kompjuterizovana medicinska slika. Naučni podmladak 1982; 14 (3-4): 123-130." 18, "Nuklearno magnetska rezonancija. Acta medica Medianae 1983; 22(1): 121-124” 19 i “Mogućnosti primene NMR u medicini. Naučni podmladak 1983; 14 (1-2): 111115 ”20,21 (slika 2). 


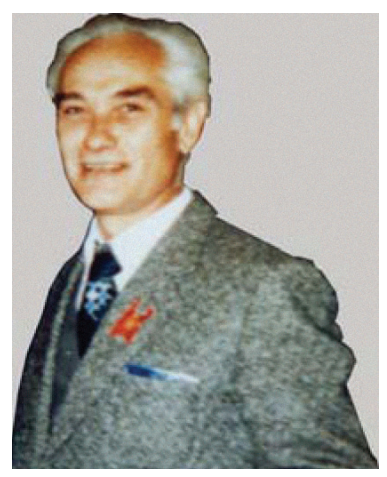

Slika 2. Prof. dr Radomir Babić, specijalista radiologije (1. decembar 1932. g., s. Desimirovac, Kragujevac, Kraljevina Jugolsavija - 7. septembra 2006. g., Niš, Republika Srbija) ${ }^{21}$

U radovima o NMR prof. dr Radomir Babić je šematski prikazao rad NMR 18-20 (slika 3).
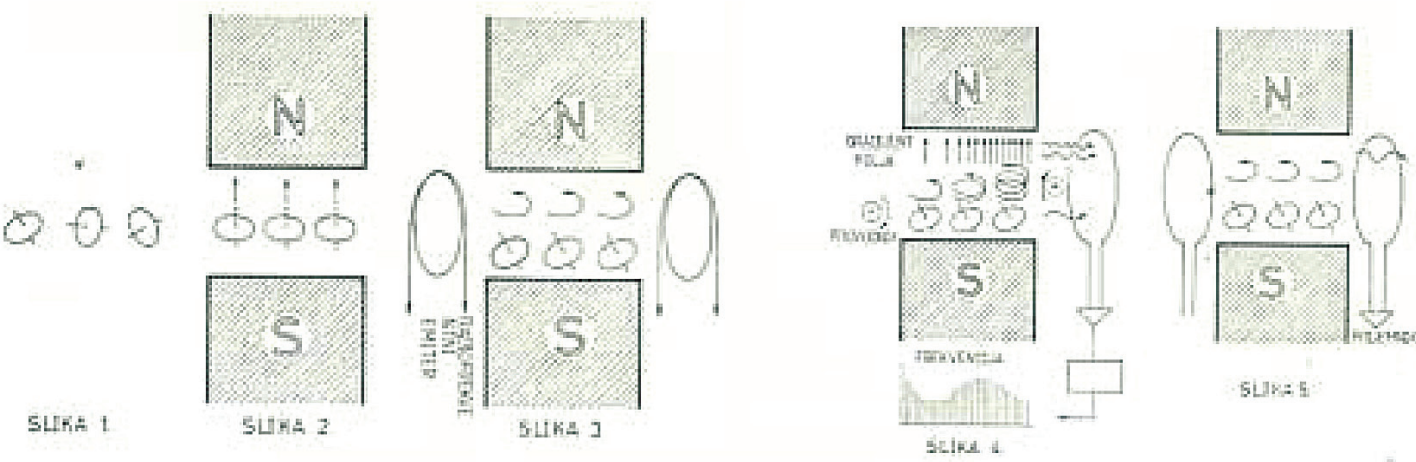

Slika 3. Šematski prikaz rada NMR.Šema iz rada prof. dr Radomira Babića - Nuklearno magnetska rezonancija. Acta medica Medianae 1983; 22(1):121-124 19

\section{Jačina magnetnog polja magnetne rezonance}

Jačina magnetnog polja MR aparata izražava se jedinicom tesla $(T)^{22-27}$. Tesla je SI izvedena jedinica za magnetnu rezonancu (gustinu magnetnog fluksa). Jedinica je nazvna u čast Nikole Tesle, koji je otkrio obrtno magnetno polje (1882.g., Budimpešta, Austrougarska Carevina). U čast Nikole Tesle jedinica za magnetnu indukciju nalazi se na papirnatoj novčanici od 100 dinara Narodne banke Srbije ${ }^{9,23}$.

Tesla je:

$$
T=\frac{V \cdot \mathrm{s}}{\mathrm{m}^{2}}=\frac{\mathrm{Wb}}{\mathrm{m}^{2}}
$$

MR aparati prema jačini magnetskog polja mogu biti: MR aparati magnetnog polja niske jačine (do $0,5 \mathrm{~T})$, MR aparati magnetnog polja srednje jačine (od 0,5 T do $1 \mathrm{~T}$ ) i MR aparati magnetnog polja visoke jačine (preko $1 \mathrm{~T}$, a mogu biti od 1,5 T, $2 \mathrm{~T}, 3 \mathrm{~T}, \ldots .7 \mathrm{~T}, 8,5 \mathrm{~T} \ldots .$. ).

U dijagnostičke svrhe koriste se MR aparati od $0,1 \mathrm{~T}$ do $4 \mathrm{~T}$, najčešće od 0,5 T do 1,5 T, dok se MR aparati preko 4 T koriste u eksperimentalne svrhe.

Radi uporedjenja ističemo da je Zemljino magnetno polje $50 \mu \mathrm{T}(0,000005 \mathrm{~T})$, dok MR aparat od 1,5 T ima magnetno polje 30.000 jače od magnetnog polja Zemlje.

$\mathrm{U}$ prirodi magnetno polje od $0,2 \mathrm{~T}$ je slabo magnetno polje, od 0,2-0,6 $\mathrm{T}$ je srednje magnetno polje, a od 1,0-1,5 $\mathrm{T}$ je visoko magnetno polje. 


\section{Fizički principi magnetne rezonance}

Nukleo magnetna rezonanca (danas: magnetna rezonanca) bazira na tri momenta:

Nulearni - radi se o spinovima atomskog jezgra;

Magnetni - homogeno magnetno polje sa magnetnim prelazima spinova nukleusa;

Rezonantni - elektromagnetnim talasom spin nukleusa se dovodi u rezonancu ${ }^{1-4,9,18-20}$.

Nukleus vodonika (1H1) tj. proton vodonika poseduje ugaoni (mehanički) moment i magnetni moment, koji zajedno predstavljaju spin (slika 4), mada se spin protona (nukeleusa) odnosi na njegov mehanički (ugaoni) moment. Spin jezgra atoma je zbir spinova protona i neutrona koji ulaze u njegov sastav. Mehanički moment i magnetni moment atoma jezgra je univerzalna osobina hemijskih elemenata. Dakle, spin se koristi za česticu kao celinu tj. za kombinaciju magnetnog i mehaničkog momenta ili spin atomskog jezgra je osobina protona i neutrona poput mase ili naelektrisanja.

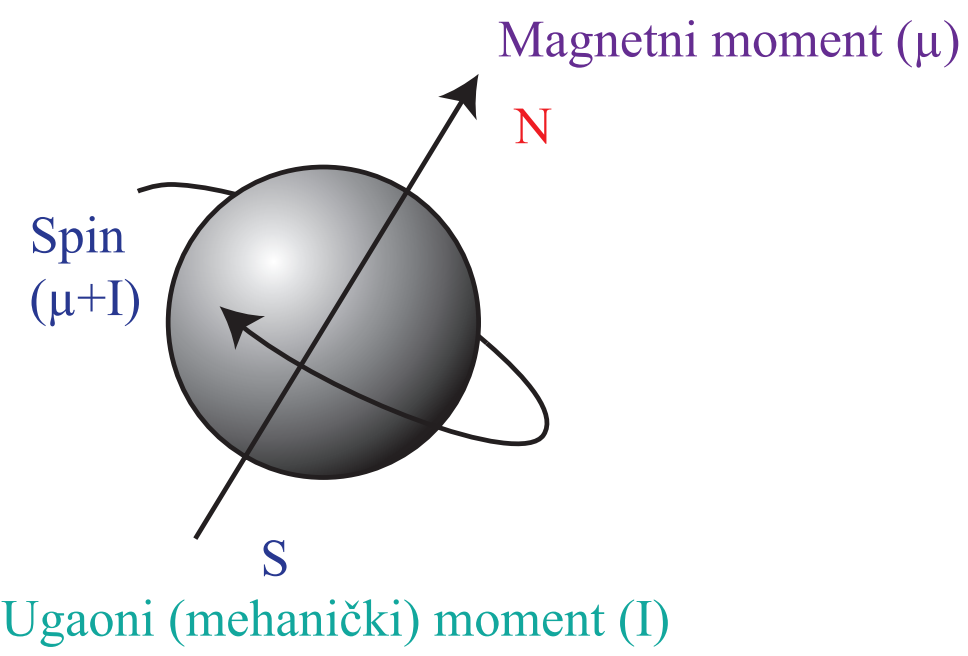

Slika 4. Jezgro vodonika poseduje spin $(\mu+$ I) tj. ugaoni moment (I) i magnetni moment $(\mu)$. Spin čestice odnosi se na njen mehanički moment. Medjutim, često se naziv koristi i za česticu kao celinu tj. za kombinacuju magnetnog i mehaničkog momenta. Spin atomskog jezgra je zbir spinova protona i neutrona koji ulaze u njegov sastav.

Atomska jezgra sa parnim brojem protona i parnim brojem neutrona nemaju magnetni moment, kao što su helijum (4He), ugljenik (12C), kiseonik (16O) i dr.

U odsustvu spoljašnjeg magnetnog polja nuklearni spin je praktično nevidljiv. Unet u magnetno polje, nuklearni spin se orjentiše, poput magnetne igle kompasa u magnetnom polju Zemlje. Zbog kvantne prirode moguće su samo diskretne orjentacije spinova čiji je broj definisan spinskim kvantnim brojem.

Spin poseduje mehanički moment, dakle ponaša se kao čigra. Po analogiji, kao što Zemljino gravitaciono polje ne može da obori čigru dok se okreće već je navodi na procesiono kretanje, tako i spoljašnje magnetno polje ne može u potpunosti da orjentiše spin već ga navodi na procesiono kretanje (slika 5). Dakle, u spoljašnjem magnetnom polju spin precesuje oko pravca polja nagnutog pod odredjenim uglom. Pri tome je procesiona frekvencija jednaka rezonantnoj frekvenciji. 


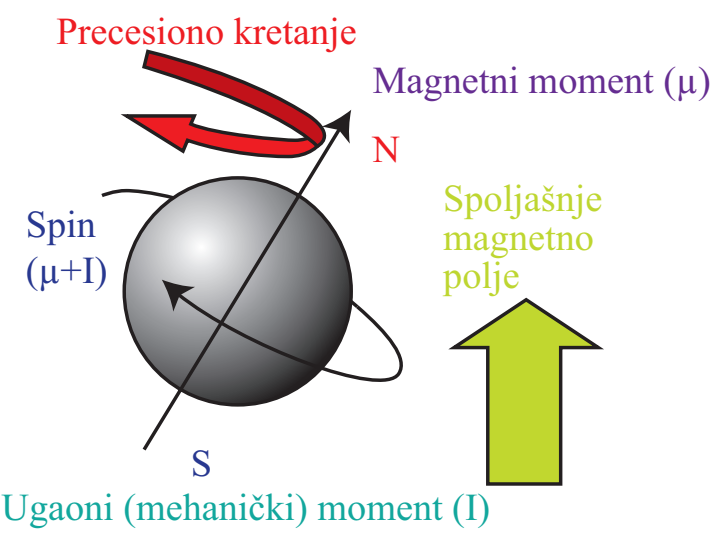

Slika 5. Proton vodonika poseduje spin ili ugaoni momet i magnetni dipolni moment. Kada se proton vodonika nadje u magnetnom polju, obrtni moment deluje na proton vodonika i uzrokuje da se zbog kvantne prirode spin u magnetnom polju orjentiše u smeru magnetnog polja (paralelno) ili suprotno magnetnom polju (antiparalelno).

Energija spina u spoljašnjem magnetnom polju zavisi od ugla koji spin zaklapa sa magnetnim poljem. Svakom uglu odgovara odredjena energija, pa su energetska stanja spina podeljena na diskretne dobro definisane nivoe. Energetska razlika medju susednim nivoima zavisi od prirode spinova i jačine (indukcije) spoljašnjeg magnetnog polja. Što je jače polje to je i razlika veća.

Pod uticajem elektromagnetnih talasa spinovi iz jednog energetskog nivoa mogu da predju u drugi energetski nivo, ali samo ako je energija kvanta (elektromagnetni talas) jednaka energetskoj razlici medju nivoima.

Pošto je broj spinova u nižem energetskom nivou veći od broja spinova u višem energetskom nivou, ukupan rezultat je da prilikom rezonance dolazi do apsorcije radio talasa (radiofrekvenog signala).

Apsorbovana energija elektromagnetnog talasa (radiofrekventnog signala - RF) neće ostati u pobudjenom nukleusu za dugo, već će se iz pobudjenog nukleusa osloboditi višak energije u vidu novog elektromagnetnog talasa, dok se pobudjeni nukleus vraća u svoje prvobitno stanje (slika 6). Kaže se da nukleus odjekuje u svojoj okolini. Signal koji se emituje u okolinu je odjek. Odjeci se detektuju, analiziraju i obradjuju i uz pomoć kompjutera pretvaraju u MR sliku (tomogram, sken ili presek).
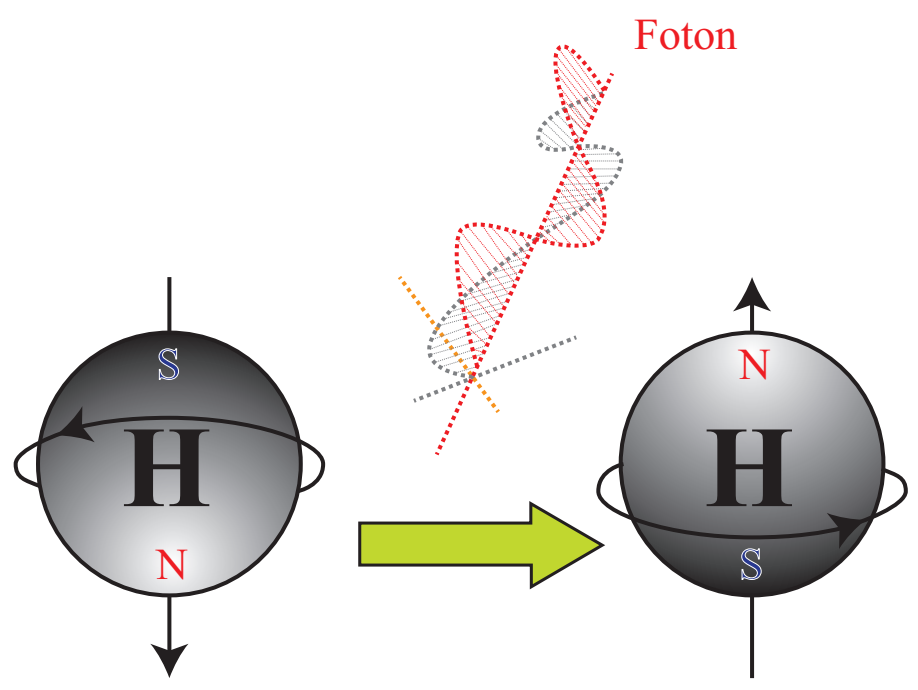

Slika 6. Apsorbovana energija elektromagnetnog talasa neće ostati u pobudjenom nukleusu za dugo, već se iz pobudjenog nukleusa oslobadja u vidu viška energije, u vidu novog elektromagnetnog talasa. Pobudjeni nukleus se vraća u svoje prvobitno stanje. U tom trenutku nukeus odjekuje, a signal koji se emituje je odjek. 


\section{Princip rada magnetne rezonance}

Rad MR zasniva se na kretanju protona iz jezgra vodonika koji sadrži spin tj. mehanički moment i magnetni moment. Koriste se atomi vodonika u molekulima vode i lipida. Vodonikovog atoma u ljudskom telu praktično ima u izobilju (oko 63\%) pa ga je lako iskoristiti u dijagnostičke svrhe.

U prirodnim uslovima vodonici $\left({ }^{1} \mathrm{H}_{1}\right)$ vode i lipida kada nisu u magnetnom polju ponašaju se kao slobodni magneti, nasumice orjentisani (slika 7).

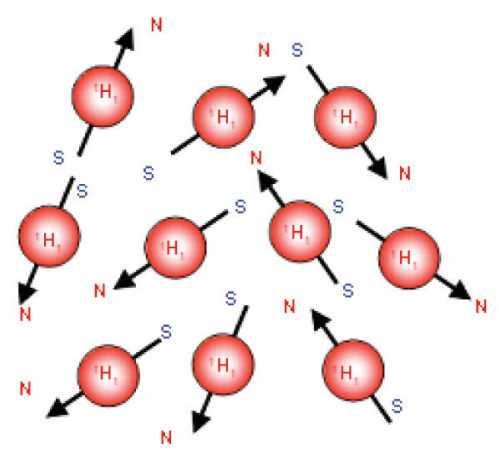

Slika 7. Nukleusi vodonika $\left({ }^{1} \mathrm{H}_{1}\right)$ vode i lipida kada nisu u magnetnom polju ponašaju se kao slobodni magneti, nasumice su orjentisani ${ }^{2}$

Kada se nadju u magnetnom polju jezgra vodonika počinju da se ponašaju kao čigra. Spin vodonikovog jezgra se navodi na procesiono kretanje i nalazi se u karakterističnoj frekvenciji poznatoj kao Larmer-ova frekvencija (slika 8).

Energija spina u spoljašnjem magnetnom polju, zavisi od ugla koji spin zaklapa sa megnetnim poljem. Spin nukleusa može da se nadje u dva energetska nivoa - spin gore (paralelan magnetnom polju) i spin dole (antiparalelan magnetnom polju). Spin gore je manjeg energetskog nivoa od spin dole.

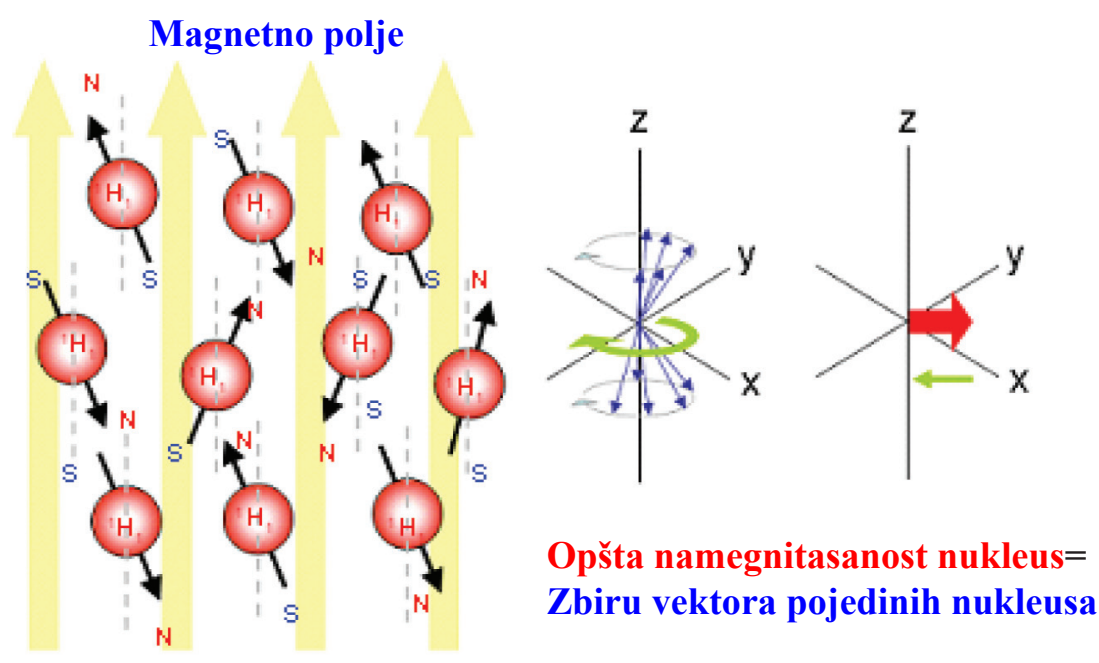

Slika 8. Nukleusi vodonika se u spoljašnjem magnetnom polju procesiono kreću. Javljaju se dva energetska nivoa - spin gor i spin dole ${ }^{2}$

Spinovi iz jednog energetskog nivoa mogu da predju u drugi pod uticajem elektromagnetnih talasa (radiofrekvencije - RF), pod uslovom da je energija elektromagnetnog talasa jednaka energetskoj razlici medju nivoima (Slika 9). 
Apsorbovana energija elektromagnetnog talasa (radiofrekventni signal - RF) neće ostati u pobudjenom nukleusu za dugo, već će se osloboditi višak energije u vidu novog elektromagnetnog talasa. Pobudjeni nukleus se vraća u svoje prvobitno stanje emitujući radiofrekventni signal (elektromagnetni talas) u svoju okolinu, pa se kaže da nukleus odjekuje. Ovi RF signali se detektuju, analiziraju i obradjuju i uz pomoć komjutera i daju u vidu slike (slika 10).
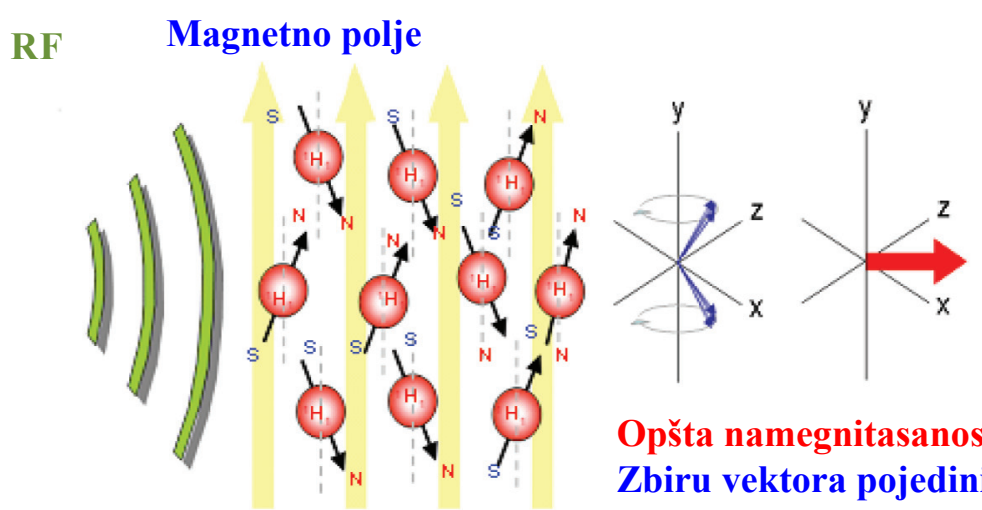

Opšta namegnitasanost nukleus= Zbiru vektora pojedinih nukleusa

Slika 9. Spinovi nukelusa vodonika pod uticajem radio frekventnog signala (RF) prelaze iz jednog energetskog nivoa $u$ drugi energetski nivo ${ }^{2}$

\section{Magnetno polje}

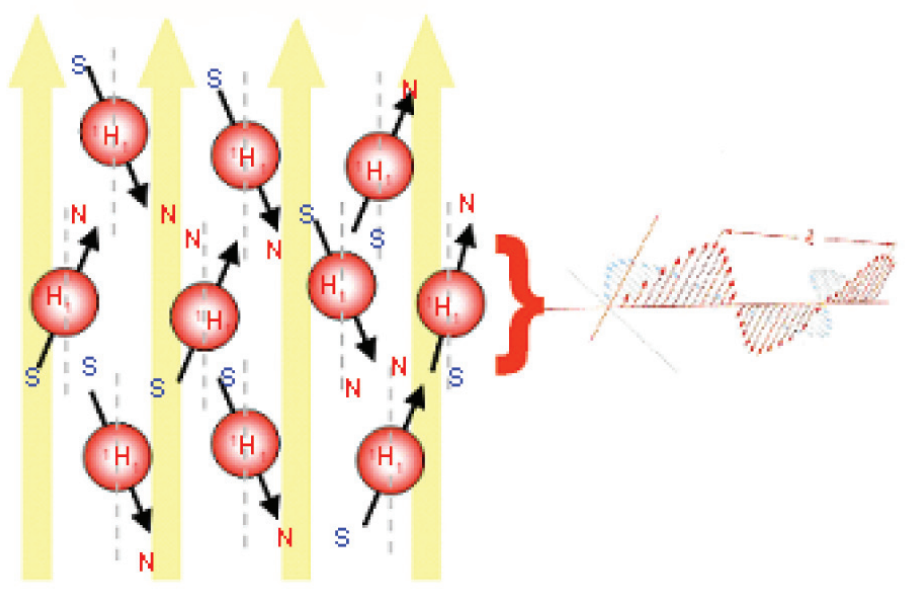

Slika 10. Apsorbovana energija radiofrekventnog signala (RF) oslobadja se kao višak energije u vidu elektromagnetnog talasa, dok se pobudjeni nukleus vraća u svoje prvobitno stanje, a oslobodjena energija u vidu elektromagnetnog talasa emituje se u okolinu, pa se kaže da nukleus odjekuje

Postoji još nekoliko parametara koji utiču ne odnos signala koje emituju pojedini delovi tela. Najvažniji od njih su vremena kada se registruje električni impuls u namotaju, kao i vreme izmedju dve indukcije RF talasima (protoni tkiva prolaze kroz dva različita vremena relaksacije):

- T1 relaksaciono vreme ogleda se u činjenici da po prestanku dejstva RF talasa jezgre protona se vraćaju u prethodnu relaksaciju. Energija se predaje okolini (spin-rešetka). Uspostavlja se longitudinalna relaksacija. Relaksacija ide po eksponencionalnom zakonu. Uzima se vreme potrebno da se obnovi $63 \%$ od maksimalne longitudinalne magnetizacije. MR sliku T1 relaksacionog vremena daju masti. MR slika dobijena u T1 relaksacionom vremenu je obrnuta od MR slika dobijenih u T2 relaksacionom vremenu. MR slika u T1 relaksacionom vremenu je slična CT skenu. Tako npr. moždane komore zbog obilja vode (cerebrospinalne tečnosti) su tamne tj. crne (слика 11). 


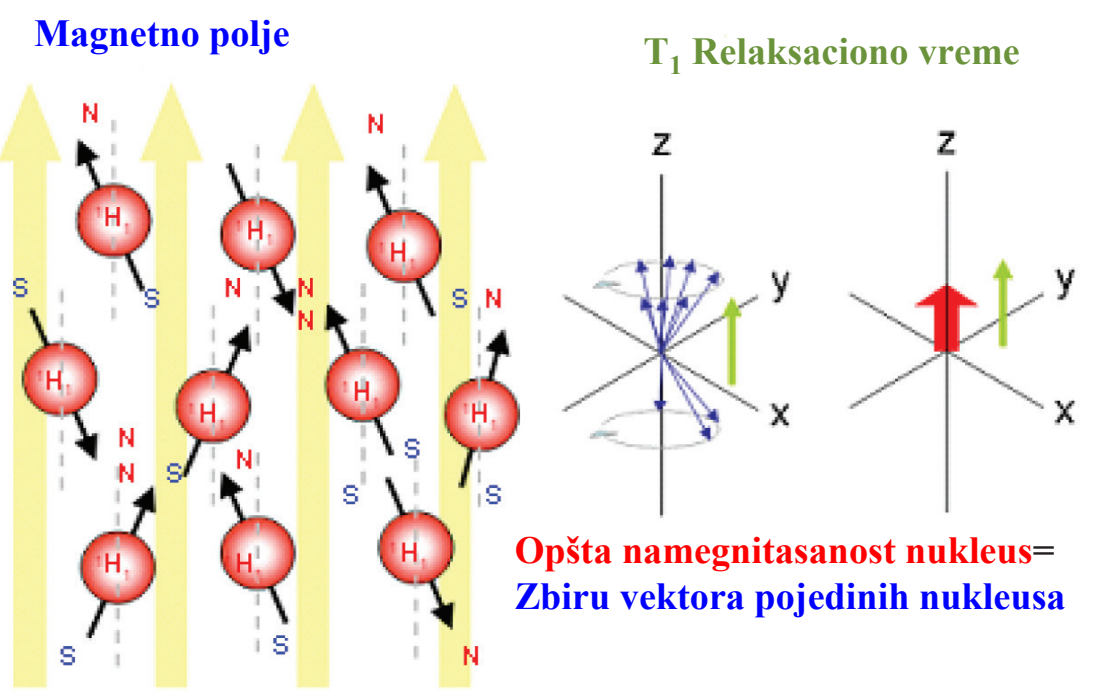

Slika 11. T1 relaksaciono vreme 2

- T2 relaksaciono vreme (slika 12) ogleda se u činjenici da nakon prestanka dejstva RF talasa protoni prestaju sinhrono da se kreću. Sve je manje protona usmereno u istom pravcu. Nastaje interakcija izmedju molekula (spin-spin). Beleži se vreme potrebno da se transverzalna magnetizacija smanji na 37\%. MR slika dobijena u T2 relaksaciono vreme daje voda (H2O), npr. cerebrospinalna tečnost. MR slika u T2 relaksacionom vremenu je obrnuta od MR slike u T1 relaksacionom vremenu. Moždane komore zbog obilja vode (cerebrospinalne tečnosti) su svetle, tj. bele (слика 11).

Razlićita tkiva imaju različito trajanje T1 i T2 relaksacionog vremena.

Kombinacijom virtualnih slika T1 i T2 vremenu rezolucije dobija se platforma kombinacija digitalnih slika.

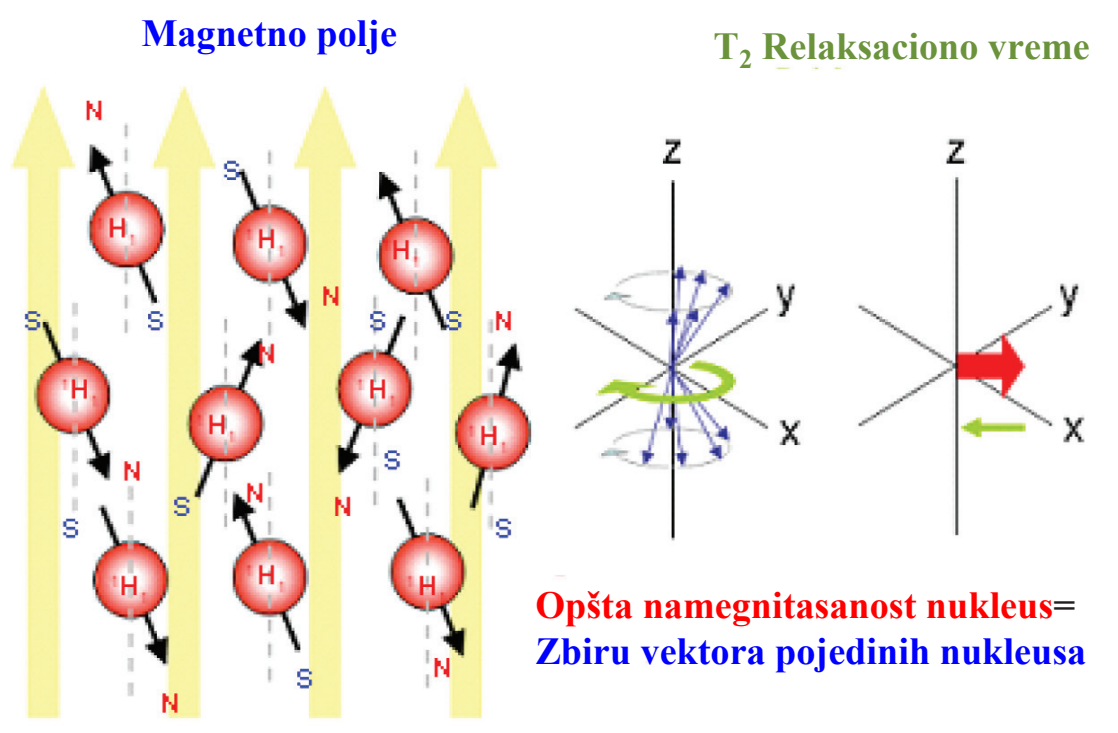

Slika 12. $T 2$ relaksaciono vreme ${ }^{2}$ 


\section{Sekvence magnetne rezonance}

Sekvence (tehnike snimanja) magnetne rezonance su brojne i raznovrsne ${ }^{9}$. Baziraju na osnovnim principima rada MR. Čine ih:

I Sekvence MR koje krosite spin:

- Spin-echo (SE) imaging;

- Fast Spin - echo (FSE) imaging;

- Inversion Recovery (IR) imaging;

- Fluid Attenuated Inversion Recovery (FLAIR) imaging;

- Short Tau Inversion Recovery (STIR) imaging;

II Sekvence MR koje koriste gradijent:

- T2* Weighted imaging;

- Steady-State Free Precession (SSFP) imaging;

- Fast Low Angle Shot (FLASH) imaging;

III Ostale (posebne) sekvence MR:

- Magnetic Resonance Cholecysto-Pancreatography (MRCP);

- Magnetic Resonance Imaging Angiography (MRA);

- Functional Magnetic Resonance Imaging (fMRI);

- Magnetic Resonance Spectroscopy (MRS);

- Diffusion Weighted Imaging (DWI)

- Diffusion Tenzor Imaging (DTI) MRI

- Tractography Imaging (TI).

Sa razvojem računarske opreme za očekivati je napredak i poboljšanje postojećih sekvenci i pojavu novih sekvenci MR.

\section{Zaključak}

Magnetna rezonanca je suverena, dominantna i nejonizujuća radiološka metoda pregleda. Magnetna rezonanca predstavlja budućnost radiološke diijagnostike. Rad MR zasniva se na primeni jakog homogenog magnetnog polja i savremene računarske tehnike. MR predstavlja minijaturan radiološki informacioni sistem. MR je nejonizujuća, neinvazivna radiološka metoda pregleda, kojom se vizualizuju i dijagnostikuju anatomska, morfološka i funkcionalna stanja organa ljudskog tela. MR pruža pregled centralnog nervnog sistema, grudnog koša, abdomena, male karlice, ekstremiteta, žučnih puteva, krvnih sudova, zglobova, dojke i dr. U primeni su sekvence (tehnike pregleda) MR koje krosite spin (Spin-echo (SE) imaging; Fast Spin - echo (FSE) imaging; Inversion Recovery (IR) imaging; Fluid Attenuated Inversion Recovery (FLAIR) imaging; Short Tau Inversion Recovery (STIR) imaging), koje koriste gradijent (T2* Weighted imaging; Steady-State Free Precession (SSFP) imaging; Fast Low Angle Shot (FLASH) imaging) i ostale (posebne) sekvence MR (Magnetic Resonance Cholecysto-Pancreatography (MRCP); Magnetic Resonance Imaging Angiography (MRA); Functional Magnetic Resonance Imaging (fMRI); Magnetic Resonance Spectroscopy (MRS); Diffusion Weighted Imaging (DWI); Diffusion Tenzor Imaging (DTI) MRI; Tractography Imaging (TI) i dr.). MR zahteva školovan kadar i adekvatno znanje iz medicine, fizike, informatike i dr. MR je samo jedna od karika savremenog radiološkog informacionog sistema (RIS). Sa razvojem računarske opreme za očekivati je napredak i poboljšanje postojećih sekvenci i pojavu novih sekvenci MR. Tehnike snimanja u MR obogatile su radiološku sliku patoloških stanja pojedinih organa. 


\section{Literatura}

1. Magnetna rezonantna tomografija. http://sr.wikipedia.org (Otvoreno: децмбар 2013)

2. MRI basics http://www.cardiff.ac.uk/biosi/researchsites/emric/basics.html

3. Felix Roland, Heshiki Atsuko, Hricak Hedving, Chang Kee-Hyun Chang, Hosten Norbert, Lemke Arne-Jörn: Magnevist. Monograph.Blackwell Science Berlin.Vienna. 2001.

4. Sudimac D. Dijana: Magnetna rezonanca. Master rad. Prirodno-matematički fakultet. Department za fiziku. Univerzitet u Nišu. Niš. 2013. http://www.pmf.ni.ac.rs

5. Smiljanić Ljubica. Difuzni tenzorski imidžing (TDI) kod bolesnika sa vaskularnom demencijom. Master rad. Departemnt za fiziku. Prirodno-matematički fakultet u Novom Sadu. Univerzitet u Novom Sadu. Novi Sad. 2011.

6. Zhukov L, Barr A: Oriented Tensor Reconstruction: Tracing Neural Pathways from Diffusion Tensor MRI. IEEE Visualization 2002, Proceedings of Vis 2002, pp 387-394, 2002.

7. Cekić Sonja, Risimić Dijana, Stanković-Babić Gordana, Babić Rade, Jakšić Vesna, Jovanović Ivan, Djordjević-Jocić Jasmina: Papilledema as a diagnostic challenge - report of three cases. Central European Journal of Medicine 2012; 7 (1). 103-107.

8. Babić Strahinja. Zdravstveni informacioni sistem. Seminarski rad. Medicinski fakultet. Univerzitet u Nišu. Niš. 2012.

9. Babić Strahinjia, Ivanković Nemanja: Tehnike snimanja u magnetnoj rezonanci. Seminarski rad. Medicinski fakultet. Univerzitet Niš. 2013.

10. Babić R Rade, Milošević Zoran, Djindjić Boris, Stanković Babić Gordana: Radiološki informacioni sistem. Acta Medica Medianae 2012; 51 (4): 39-46.

11. Babić R Rade, Milošević Zoran, Stanković Babić Gordana: Web technology in health information system Acta Facultatis Medicinae Naissensis 2012; 29 (2): 81-87..

12. Babić R Rade, Milošević Zoran, Stanković Babić Gordana: Teleradiology - radiology at distance Acta Facultatis Medicinae Naissensis 2012; 29 (3): 145-151.

13. Strahinjić Spira, Babić R. Rade: Prevencija bubrežnih bolesti. Udžbenik. Medicinski fakultet Niš. Univerzitet u Nišu. Sven - Niš. Niš. 2012.

14. Edward Mills Purcell. http://en.wikipedia.org/wiki/Edward_Mills_Purcell

15. Felix Bloch http://sr.wikipedia.org/sr/

16. Paul Christian Lauterbur. http://en.wikipedia.org/wiki/Paul_Lauterbur

17. Sir Peter Mansfield. http://en.wikipedia.org/wiki/Peter_Mansfield

18. Babić Radomir. Kompjuterizovana medicinska slika. Naučni podmladak 1982; 14 (3-4): 123-130.

19. Babić Radomir. Nuklearno magnetska rezonancija. Acta medica Medianae 1983; 22(1): 121-124.

20. Babić Radomir. Mogućnosti primene NMR u medicini. Naučni podmladak 1983; 14 (1-2): 111-115

21. Dušan Mitrović. In memoriam Radomir M Babić (1932-2006). Acta medica Medianae 2006; 44 (4): 67.

22. Tesla (jedinica): http://sr.wikipedia.org/sr

23. Babić RR, Stanković-Babić Gordana. Medicina u notafiliji - III deo. Medicinski pregled 2013; 66 (5-6): $268-272$.

24. Babić RR. Tesla o X-zracima. Vojnosanitetski pregled. 2006; 11: 979-982.

25. Babić RR. Nikola Tesla i X-zraci. Acta Medica Medianae 2004; 4: 81-82.

26. Babić RR. Nikola Tesla i osnove rendgenografiranja. Acta Medica Medianae 2005; 1: 85-87.

27. Babić RR. Nikola Tesla o štetnom dejstvu X-zraka. Acta Medica Medianae 2005; 3:67-69.

Prof. Rade R. Babić, radiolog posao: Centar za radiologiju KC Niš

Bulevar dr Zorana Đinđića br. 48

Tel: 018/4202040

18000 Niš, Srbija

gordanasb@open.telekom.rs 